\title{
Delay for first consultation and associated factors among tuberculosis patients in Bahir Dar town administration, North West Ethiopia
}

\author{
Yeshiwork Amogne Mekonnen ${ }^{1,4}$, Lakew Abebe ${ }^{2}$, Netsanet Fentahun ${ }^{2}$, Shegaw Alemu Belay ${ }^{4}$, \\ Addisu Workineh Kassa ${ }^{3,4}$ \\ ${ }^{1}$ Health promotion and disease prevention, Bahir Dar, Ethiopia \\ ${ }^{2}$ Jimma University, Jimma, Ethiopia \\ ${ }^{3}$ Public Health Emergency Management, Bahir Dar, Ethiopia \\ ${ }^{4}$ Regional Health Bureau, Bahir Dar, Ethiopia
}

Email addresses:

yeshi2124@gmail.com (Y. A. Mekonnen)

To cite this article:

Yeshiwork Amogne Mekonnen, Lakew Abebe, Netsanet Fentahun ,Shegaw Alemu Belay, Addisu Workineh Kassa. Delay for First Consultation and Associated Factors among Tuberculosis Patients in Bahir Dar Town Administration, North West Ethiopia.

American Journal of Health Research. Vol. 2, No. 4, 2014, pp. 140-145. doi: 10.11648/j.ajhr.20140204.16

\begin{abstract}
Background: Delayed presentation for first consultation is a major problem contributing to the high burden and transmission of tuberculosis in most developing countries including Ethiopia. There is paucity of evidence on the magnitude of patient delay and why patients fail to seek care in health institution early in Bahirdar town administration area. Objective: To determine the delay for first consultation and its associated factors among tuberculosis patients in Bahir Dar town health facilities. Methods: A facility based cross-sectional study was conducted from 10 March - 08 May 2012 in Bahirdar town administration health facility. For quantitative part a total of 315 study participants were included. For qualitative part, eighteen study participants of family members were participated. Data were collected from newly diagnosed TB patients. Data were entered and analyzed using SPSS version 16 window. Multivariate logistic regression analysis was used to identify factors associated with patient delay. Result: The magnitude of patient delay was 165(52.4\%) and median of patient delay was 30 days within range of 3 to 270 days. Illiterate ( $\mathrm{AOR}=6.18,95 \% \mathrm{CI}: 1.34,28.43$ ), extra pulmonary tuberculosis ( $\mathrm{AOR}=10.12$, 95\% CI:3.07, 33.37), living greater than a distance of $10 \mathrm{~km}$ from TB service in health facilities ( $\mathrm{AOR}=3.55,95 \% \mathrm{CI}: 1.17,10.80)$, prior visited , with holy water $(\mathrm{AOR}=10.55,95 \% \mathrm{CI}: 3.99,27.89)$, with traditional healer ( $\mathrm{AOR}=4.29,95 \% \mathrm{CI}: 1.13,16.37$ and with private drug store/pharmacy ( $\mathrm{AOR}=6.81,95 \% \mathrm{CI}: 2.47,18.78)$ were determinants of patients delay for first consultation in health facilities. Conclusion: The magnitude of patient delay was generally higher than most African and other developing countries. More than half, $54.6 \%$ of tuberculosis patients delayed seeking health care at health facility while getting treatment from informal sources of treatment. Health promotion and education involving different stake holders will make the community to create awareness about tuberculosis could help reduce delays in starting modern treatment was recommended.
\end{abstract}

Keywords: Patient Delay, Factors, Tuberculosis, First Consultation, Health Facilities

\section{Introduction}

Tuberculosis (TB) is a chronic infectious disease that has major public health problem globally and it caused by Mycobacterium tuberculosis [1]. Almost one-third of the world population (about 2 billion) is infected with $\mathrm{M}$. tuberculosis[1]-[3]. Although relatively small proportion of people this infected with Mycobacterium tuberculosis will go on to develop TB disease all of them are a candidate to develop active tuberculosis[1]-[4] Ethiopia ranks seventh among the world's 22 high-burden tuberculosis (TB) countries[4]. Thus case finding is depending on the patients themselves to present to the health facility when they suspect that they have symptoms of tuberculosis. But this is highly affected by the patient's knowledge on tuberculosis symptoms, readiness and decision to visit health care 
providers [5]- [7].

From the perspective of country's economy patient delay highly affect the country's economy through increasing the disability and death of productive age group due to TB [8], [9] Late diagnosis and delayed initiation of treatment of pulmonary tuberculosis intern increases the risk of developing more severe and harder-to-treat forms of TB, and also increases the risk of ongoing transmission. This all can result in a higher risk of mortality among patients and transmission of the disease in the community[3], [5]- [7]\& [10]. Evidence of related literature revealed that patient's first presentation to health facilities more than 30 days and health seeking behaviour influencing in different factors. [6], [11]- [14].

Understanding the magnitude and the factors associated with patient delays is of paramount importance to the realization of the new Global Plan to Stop TB, which aims to halve the prevalence and death rates from TB by 2015 [15]. However, very little is known about the magnitude and associated factors with patient delay in Ethiopia.

Patient delay, the time from onset of symptoms to first consultation to modern health care, is alarmingly prolonged with studies reporting from 2 to 4 months [11]- [13], [16][23] and some studies have been reported that patient delay reported more than $50 \%$ of the study participants from onset of symptom to visit health care facilities[16], [18] , [19] Achieving the country goal of the stop TB strategy require active community participation by provision of information through different media[24]-[26].A number of factors have been reported to be associated with delay. Some of these factors stigma and illiteracy in educational status[17], [25], [27]- [30] distance and age group greater than or equal to forty five[18],[20], [23], [27].Extra pulmonary tuberculosis in classification of all types of TB[12], [18], [22] and alternative source of treatment[6], [19], [20] and inadequate awareness of TB[11], [12], [18], [19].

The objective was to assess tuberculosis patient's delay for first consultation and associated factors in health facilities of Bahir Dar town Administration. Therefore this study will help policy makers and program implementers to mitigate the problem and could be the base line evidence for further study.

\section{Methodology}

\subsection{Study Area}

The study was conducted in Bahirdar town which is the capital city of Amhara national regional state. It is located at $565 \mathrm{~km}$ North West of Addis Abeba Ethiopia. The town has a population of 255,779 and 59,483 house hold at family size 4.3 person per house hold (30).There were 9 public health facilities (one hospital and eight health center) and two private hospital in Bahirdar town administration at a time of study period .Eight health center were provide smear microscopy and three hospital had both radiographic and smear microscopy service were currently to provide TB diagnostic and treatment service based on DOTS program.

\subsection{Study Design}

Facility based cross-sectional study was conducted using both quantitative and qualitative methods.

\subsection{Study Period}

The study was conducted from 10 March -08 May 2012.

\subsection{Sample Size and Sampling Technique}

For quantitative part, the sample size was determined using single population proportion formula $\left(n=\left[\left(Z_{\alpha / 2}\right) 2 * p\right.\right.$ $\left.*(1-p)] / d_{2}\right)$ where: $Z \alpha / 2$ at $95 \% \mathrm{CI}(1.96), \mathrm{d}$ marginal error $0.05, \mathrm{p}$ proportion obtained from previous study in Tigray of Northern Ethiopia[12] .Taking 10\% 0f non-respondent rate, the total sample size of the study participant was 317. The study population was adult TB patients newly diagnosed whose age 15 years and above included in the study. Patients who are critically ill and unable to respond were excluded from the study because they may not give appropriate response for the questionnaire. The study participants were employed to select consequently in selected health facilities. More over to avoid double counting, reminder note was attached with referral sheet to the receiving health facilities. For qualitative part, eighteen participants were undertaken on purposively selected by principal investigator and a semi-structured open ended interview guide was adopted[31] and used for in-depth interview.

\subsection{Data Collection Tools and Quality Assurance}

Data were collected using structured questionnaire adapted from pertinent literature and which contained a questions of socio demographic, perception and knowledge about TB, internalized stigma, availability and accessibility of health facilities, how the decision was made to visit health facilities, source of information about TB and onset of current illness to visit health facilities for the first time (delay) were include. The questionnaire was prepared in English first and translated to the local language, Amharic and again back to translation to English was made to ensure that the consistency of the question. Pretest was done on 5\% of the sample size in the area different from the study area before actual data collection.

\subsection{Data Analysis}

Questions were coded and then data were entered and analyzing using SPSS Version 16. Frequency, cross tabulation and sort were checked for data quality management. Descriptive statistics was used to summarize data, tables and figures for display results .Bivariate and multivariate analysis was used to identify associated factors of patient satisfaction and the strength of association measured by $95 \%$ Confidence interval and P-value of 0.05 
was used as a cut of point.

\subsection{Ethical Consideration}

Ethical clearance and approval was obtained from the Ethical review Committee of the College of Public Health and Medical Sciences, Jimma University. Permission was obtained from Amhara Regional Health Bureau and the respective health facilities. Informed verbal consent was obtained from study participants. Confidentiality and anonymity were ensured.

\section{Results}

\subsection{Socio-Demographic Characteristics of Respondents}

A total of 317 study participants participated from selected health facilities during data collection period, however, two study participants were excluded from the study because the collected data were found incomplete. (Table1).

Table 1.Socio-demographic characteristics of TB patients in Bahir Dar town administrative health facilities from March10-May 08, 2012

\begin{tabular}{|c|c|c|c|}
\hline Variable & & Frequency(№) & Percentage $(\%)$ \\
\hline \multirow{2}{*}{ Sex of respondents } & Male & 181 & 57.5 \\
\hline & Female & 134 & 42.5 \\
\hline \multirow{4}{*}{ Age in years } & $15-24$ & 76 & 24.1 \\
\hline & $25-34$ & 105 & 33.3 \\
\hline & $35-44$ & 69 & 21.9 \\
\hline & $>=45$ & 65 & 20.6 \\
\hline $\operatorname{Mean}(\mathrm{SD})$ & & $33.9( \pm 12.8 \mathrm{SD})$ & \\
\hline Range & & $15-73$ & \\
\hline \multirow{2}{*}{ Residence } & Rural & 179 & 56.8 \\
\hline & Urban & 136 & 43.3 \\
\hline \multirow{4}{*}{ Education } & Illiterate & 115 & 49.2 \\
\hline & Read and write & 40 & 12.7 \\
\hline & Primary- secondary & 89 & 28.3 \\
\hline & Collage \& above & 31 & 9.8 \\
\hline \multirow{6}{*}{ Occupation } & Farmer & 94 & 29.8 \\
\hline & House wife & 80 & 25.4 \\
\hline & Employee* & 64 & 20.3 \\
\hline & Merchant & 28 & 8.9 \\
\hline & Student & 25 & 7.9 \\
\hline & Daily laborer & 24 & 7.6 \\
\hline \multirow{2}{*}{ Religion } & Orthodox & 276 & 87.6 \\
\hline & Muslim & 39 & 12.4 \\
\hline \multirow{3}{*}{ Ethnicgroup } & Amhara & 307 & 97.5 \\
\hline & Oromo & 3 & 1.0 \\
\hline & Tigre & 5 & 1.5 \\
\hline \multirow{4}{*}{ Marital status } & Married & 199 & 63.2 \\
\hline & Single & 77 & 24.4 \\
\hline & Divorced & 24 & 7.6 \\
\hline & Windowed & 15 & 4.8 \\
\hline
\end{tabular}

Employee*: Government, Non-government and private organization

\subsection{Determinants of Patient Delay for First Consultation in Health Facilities}

Multivariate logistic regression analysis was carried out in order to identify the independent determinant of patient delay in health facilities. Those variables which had $\mathrm{P}$ value of less than 0.05 in bivariate analysis were entered in multivariate analysis. Step wise back ward logistic regression method was employed. Among those education, types of TB, distance and different alternative informal source of treatment before went to health facilities were significant predictor of patient delay. However, place of residence, knowledge, marital status, attitude, Internalized stigma and costs that hinder to seek health care in health institution (affordability) had association in the bivariate analysis by controlling other variables the association turned insignificant.

Extra pulmonary TB patients were ten times more likely to be delayed than those the study participants with smear positive pulmonary $\mathrm{TB}$ were $(\mathrm{AOR}=10.12,95 \% \mathrm{CI}: 3.07$, 33.78).

Patients who lived beyond 10 kilometer radius from TB service in health facilities $(\mathrm{AOR}=3.55,95 \% \mathrm{CI}: 1.17,10.80)$ were three times more delayed than those with in $10 \mathrm{Kms}$ radius. The use of prior treatment with holy water (AOR $=10.55,95 \%$ CI: 3.99, 27.89), traditional healer $(\mathrm{AOR}=4.29,95 \% \mathrm{CI}: 1.13,16.37$ and by private drug store/pharmacy $(\mathrm{AOR}=6.81,95 \% \mathrm{CI}: 2.47,18.87)$ were significantly associated with patient delay (Table 2). 
Table 2. Determinants of patient delay for first consultation among TB patients in Bahirdar town health facilities from March10 to May 8, 2012.

\begin{tabular}{|c|c|c|c|c|c|}
\hline Variable & & Not Delayed No (\%) & Delayed No (\%) & COR(95\%CI) & $\operatorname{AOR}(95 \% C I)$ \\
\hline \multirow{4}{*}{ Age in years } & $15-24$ & $41(27.3)$ & $35(21.2)$ & 1.0 & 1.0 \\
\hline & $25-34$ & $64(42.7)$ & $41(24.8)$ & $0.75(0.41,1.36)$ & $0.84(0.26,2.76)$ \\
\hline & $35-44$ & $29(19.3)$ & $40(24.2)$ & $1.62(0.84,3.12)$ & $0.92(0.22,3.91)$ \\
\hline & $>=45$ & $16(10.7)$ & $49(29.7)$ & $3.59(1.74,7.39)^{*}$ & $1.79(0.37,8.81)$ \\
\hline \multirow{2}{*}{ Residence } & Urban & $91(60.7)$ & $45(27.3)$ & 1.0 & 1.0 \\
\hline & Rural & $59(39.3)$ & $120(72.7)$ & $4.11(2.56,6.61)^{* *}$ & $1.13(0.38,3.32)$ \\
\hline \multirow{4}{*}{ Education } & Collage $\&$ above & $28(18.7)$ & $3(1.8)$ & 1.0 & 1.0 \\
\hline & Primary- secondary & $55(36.7)$ & $34(20.6)$ & $5.77(1.63,20.45)^{*}$ & $2.47(0.58,10.46)$ \\
\hline & Read and write & $22(14.7)$ & $18(10.9)$ & $7.64(1.99,29.27)^{*}$ & $2.47(0.49,12.23)$ \\
\hline & Illiterate & $45(30)$ & $110(66.7)$ & $22.82(6.6,78.8)^{* *}$ & $6.18(1.34,28.43)^{*}$ \\
\hline \multirow{4}{*}{ MaritalStatus } & Married & $94(62.7)$ & $105(63.6)$ & 1.0 & 1.0 \\
\hline & Single & $46(30.7)$ & $31(18.8)$ & $0.60(0.351 .03)$ & $1.93(0.69,5.36)$ \\
\hline & Divorced & $6(4)$ & $18(10.9)$ & $2.69(1.02,7.05)^{*}$ & $0.94(0.19,4.62)$ \\
\hline & Window & $4(2.7)$ & $11(6.7)$ & $2.46(0.76,7.99)$ & $7.02(0.85,57.60)$ \\
\hline \multirow{3}{*}{ TB category } & $\mathrm{PTB}+$ & $69(46.0)$ & $36(21.8)$ & 1.0 & 1.0 \\
\hline & PTB- & $68(45.3)$ & $58(35.2)$ & $1.65(0.96,2.79)$ & $1.27(0.55,2.94)$ \\
\hline & Extra-PTB & $13(8.7)$ & $71(43.0)$ & $10.47(5.1,21.4)^{* *}$ & $10.12(3.07,33.37)^{* *}$ \\
\hline \multirow{3}{*}{ Knowledge } & Good knowledge & $49(42.6)$ & $15(15.5)$ & 1.0 & 1.0 \\
\hline & Fair knowledge & $61(53$ & $64(66.0)$ & $3.43(1.76,6.74)^{* *}$ & $1.16(0.37,3.60)$ \\
\hline & Fair knowledge & $5(4.3)$ & $18(18.6)$ & $11.76(3.7,37.04)^{* *}$ & $1.27(0.18,9.12$ \\
\hline \multirow{2}{*}{ Stigma } & No stigma & $78(54.5)$ & $47(33.6)$ & 1.0 & 1.0 \\
\hline & Stigma & $65(45.5)$ & $93(66.4)$ & $2.8(1.7,4.6)^{*}$ & $1.56(0.65,3.74)$ \\
\hline \multirow{2}{*}{ Distance } & $\leq 10 \mathrm{~km}$ & $135(90.0)$ & $97(58.5)$ & 1.00 & 1.00 \\
\hline & $>10 \mathrm{~km}$ & $15(10.0)$ & $68(41.2)$ & $6.31(3.40,11.6)^{* *}$ & $3.15(1.17,10.8)^{*}$ \\
\hline \multirow{2}{*}{$\begin{array}{l}\text { Cost that hinder to } \\
\text { seek TB service. }\end{array}$} & Yes & $50(33.3)$ & $82(49.7)$ & 1.0 & 1.0 \\
\hline & NO & $100(66.7)$ & $83(50.3)$ & $1.98(1.25,3.12)^{*}$ & $0.93(0.38,2.56)$ \\
\hline \multirow{4}{*}{$\begin{array}{l}\text { Where go before } \\
\text { visiting Health } \\
\text { facilities }\end{array}$} & No prior treatment & $106(70.7)$ & $37(22.4)$ & 1.0 & 1.00 \\
\hline & Holy water & $19(12.7)$ & $77(46.7)$ & $11.6(6.21,21.7)^{* *}$ & $10.6(3.9,27.8)^{* *}$ \\
\hline & Traditional healer & $8(5.3)$ & $18(10.9)$ & $6.45(2.59,16.1)^{* *}$ & $4.29\left(1.13,16.37^{*}\right.$ \\
\hline & private drug store & $17(11.3)$ & $3(20.0)$ & $5.56(2.78,11.4)^{* *}$ & $6.8(2.5,18.78)^{* *}$ \\
\hline
\end{tabular}

** Significant at $\mathrm{P}$ value $<0.0001$

* Significant at $\mathrm{P}$ value $<0.05$

Adjusted for age of respondent, residence, education, marital status, type of TB, knowledge, internalized stigma, distance, costs that hinder to seek health care, different alternative source of treatment.

\section{Discussion}

The prevalence of patient delay in this study was 52.4 percent and consistent with studies done in Tigray 53\% [19]. But the result of this study was lower than studies done in Somali region, Ethiopia (87\%) [18].The possible reason for this gap might be due to the fact that in Somalia region, where predominantly nomadic people were found in dispersed location and inaccessible to modern medical health care compare to Amhara region. The overall median patient delay in this study was 30 days. These findings are consistent with previous studies from Ethiopia [6], [11][12], [14], [19],[20], South Sudan[21], Botswana [13], Norway[22] and WHO in east Mediterranean study in Iraq (median, 31 days), Syria (median, 31 days), and Somalia . However the result of the same study in Pakistan (median, 9 days), Egypt (median, 12 days) showed that tuberculosis patients were much less delayed than in this study [23]. The possible explanation for differences in delay could probably be explained by the cultural factor, low socio economic status, low level of knowledge and awareness of the disease and lack of information about availability of free TB treatment. In this study about $89.5 \%$ of the study participants had heard of TB from different source of information. This is similar to a study done in north Ethiopia 86\%[24], Gibe research $83 \%$ [25], $90 \%$ of women and $95 \%$ of men age 15-49 have heard about TB [26]

In this study a little more than half,55.8\% of the study participants had perceived stigma of $\mathrm{TB}$ on work performance, marital prospects, social and family relationship. This study consistent with Gibe, south west Ibadan [17], Ethiopia [25], Zambia[27] and Nepal[28] .Perception of stigma might have great impact on the social, psychological and mental wellbeing of the victim and also his/her family. This was also supported by the qualitative study. A 23 years old woman in the urban area said that "If I disclose my TB status to my neighbour, I will be a victim gossip in the community and my children couldn't play with their friends and learn at school "The other person a 50 years old man in rural kebeles expressed his idea by saying that "some people in the community reduce social interaction with $T B$ patients because it is difficult to identify whether they are free from HIV or not.

Illiterate in educational status was found to be predictor of patient delay, this study which is consistent with result from Ethiopia[25], [29], [31].This could be due to the fact that those patients with no education have poorer knowledge 
about TB and thus less likely to seek health care in health facilities at the earliest time. The study participants who lived greater than $10 \mathrm{~km}$ from health facilities were found predictors of patient. This result was in line with studies done [18], [20], [23], [27].These might be related to the fact that people who lived far from health care facilities would need support from the family members or other their body to accompany them to health facilities, especially for elders and critically ill patients. Also transport cost, time, accommodation other resources would be increased and may rely on informal alternative source of treatment care for current onset of illness rather visited health facilities.

Extra pulmonary TB constituted $27 \%$ of all cases in this study. The site of the disease was the significant predictor of patient delay in unadjusted and adjusted analysis, with delays in patients with extra-pulmonary TB were more delayed to seek health care in health facilities than patients with pulmonary positive tuberculosis.

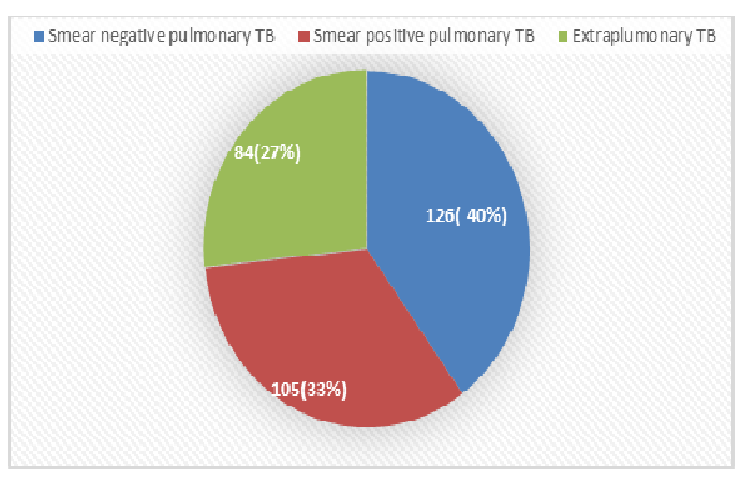

Figure 1. Types of TB among TB patients in Bahir Dar town administrative health facilities from March10-May 08, 2012

The 1st possible explanation for observed difference in Patients with extra-pulmonary TB may have a variety of symptoms, could easily be overlooked, gradual progress and less sever of clinical manifestation seeking traditional healer especially patients developed swelling in cervical lymphadenitis relative to patients with pulmonary TB and the 2nd explanation might be patients with extra pulmonary TB feel reassured about their health condition and don't proceed with necessary investigation to diagnose the condition in health facilities. This study was consistent with study done in Tigre [12], Somali [21] and Norway [26]

The use of an informal treatment/provider was a strong predictor of patient delay in this study .This finding indicated $56.4 \%$ of tuberculosis patients had sought care in health facilities after visited alternative source of treatment ( holy water ,traditional healer and private drug store) and this study was consistent with study done in Addis Abeba [6] Tigray[19], Amhara [20].The possible explanation using of alternative therapies might be related to religious beliefs of patients, in which about $87 \%$ of our study participants were orthodox Christians. The Orthodox Church, the most prominent religious institution in the study area, widely practices faith-based therapy with holy water. Patients get holy water treatment either at home or churches believed to have supernatural powers to heal the disease. The home-based treatment is prescribed by priests after praying a small volume of water to be applied over the body and sprayed inside his/her living room. An alternative approach demands patients' stay close to holy water springs that are mostly located adjoining to churches. This idea is supported by qualitative study.

A 43 years old female who was living in rural area said that "most orthodox Christian followers went to churches where holy water service is provided as initial treatment and stays for a period of time like one week or fortnight determined by priests".

\section{Conclusion}

The result of this study revealed that 52.4 percent of TB patients in this study area didn't present within 30 days from onset of illness to health facilities. Illiterate in education status, extra pulmonary TB, distance greater than ten $\mathrm{Km}$, first point of contact at traditional healer, holy water and private drugstore were found to be predictors for prolonged patient delay for first consultation in health facilities. There for, provision of health education in different stakeholder on TB should be strengthen to reduce delay and to start modern treatment early.

\section{Competing interest}

The authors declare that they have no common competing interest.

\section{Authors' Contribution}

Yehiwork A, Lakew A, Netsanet F conceived and designed the study.Yeshiwork A and Shegaw A analyzed the data and interpret the result.Yeshiwork A and addisu W prepared manuscript. All authors have read and approved this manuscript.

\section{Acknowledgments}

The authors would like to thank the data collectors for their commitment of during data collection and study participants for their willingness to participate in the study.

\section{References}

[1] WHO report 2011, Global tuberculosis Control, Surveillance, Planning and Financing, Geneva: STOP TB department WHO; 2011.

[2] Federal Ministry of Health of Ethiopia. Tuberculosis/leprosy and TB/HIV prevention and Control programme manual. 2nd ed. Addis Ababa; 2008

[3] Center for Disease Control. Questions and Answers about TB;2009:\{cited2011Sep22]http://www.cdc.gov/tb/publicatio ns/faqs/pdfs/qa.pdf. 
[4] WHO report 2009, Global tuberculosis Control, Surveillance, Planning and Financing Geneva: STOP TB department WHO; 2009.Rebaudet S, Parola P. Epidemiology of relapsing fever and Borreliosis in Europe. FEMS Immunology and Med Microbiology. 2006 Oct; 48(1):11-5.

[5] Tatek Wondimu, Kifle W/Michael, Wondwossen Kassahun, Sofonias Getachew :delay in iniating tuberculosiedtreatment and associated factors among Tuberclosis patient in East wollega, Ethiop.J.Health Dev.2007;21(2):148-156.

[6] Demissie M, Bernt Lindtjorn, Yemane Berhane. Patient and health service delay in the diagnosis of pulmonary tuberculosis in Addis Ababa, Ethiopia. BMC public health BMC Public Health 2002, 2(1):23.

[7] Tegegn A, Mcomm H, Yazachew M : patients' knowledge and belief about TB among TB patientsin Jimma zone, south west Ethiopia, EJHS,2009.

[8] Floyd K. Costs and effectiveness-the impact of economic studies on TB control. Tuberculosis 2003; 83: 187-200.

[9] Kamolratanakul, P, Sawert, H, Kongsin, S, Lermaharit, S, Sriwongsa, J, Na-Songkhla, S, Wangmanee, S, Jittimanee, S and Payanandana, V (1999) "Economic Impact of Tuberculosis at the Household Level" International Journal of Tuberculosis and Lung.

[10] Mohammed Guled Farah,Jens henning Rygh,ToreW steen,Randie semer,Einar heldal and Gunner Bjune :patient and health care system of TB treatment in Norway, $B M C$ Infectious Diseases2006, 6:33.

[11] Madebo T, Lindtjorn B: Delay in Treatment of pulmonary Tuberculosis: An analysis of symptom duration among Ethiopia patients. MedGenMed 1999, 18:E6

[12] Mesfin Mengiste M, Tasew Tesfay W, Tareke Israel G, Kifle Yohannes T, Karen Witten H, Richard Madeley J: Delays and care seeking behaviour among tuberculosis patients in Tigray of northern Ethiopia. Ethiop J Health Dev 2005, 19(Special Issue):7-12.

[13] Steen TW, Mazonde GN: Ngaka ya setswana, ngaka ya sekgoa or both? Health seeking behaviour in Botswana with pulmonary tuberculosis. Soc Sci Med 1999, 48(2):163-72.

[14] Cambanis A, Yassin MA, Ramsay A, Bertel Squire S, Arbide I, Cuevas LE: Rural poverty and delayed presentation to tuberculosis services in Ethiopia. Tropical Medicine

[15] Raviglione M \& Uplekar M (2006) WHO's new Stop TB Strategy. Lancet 367, $952-705$.

[16] Mutisya, Redempta K, Factors contributing to delay in seeking treatment among pulmonarytuberculosispatientsinKibwezidistrictKenya:http:/ /172.24.15.15:8080/etd/handle/123456789/442.

[17] A.A. FATIREGUN and C.C. EJECKAM Determinants of patient delay in seeking treatment among pulmonary tuberculosis cases in a government specialist hospital in Ibadan, Nigeria ,Tanzania journal of health research ,2010

[18] Abdi A Gele,,Gunnar Bjune and Fekadu Abebe : Pastoralism and delay in diagnosis of TB in Ethiopia, BMC Public Health 2009.

[19] Mesfin M, Newell J, Walley J, Gessessew, and Madeley Delayed consultation among pulmonary tuberculosis patients: across sectional study of 10 districts of Ethiopia, BMC Public Health 2009, 9:53

[20] Yimmer S, Bjune G, Aerlene G, Diagnostic and treatment delay among pulmonary tuberculosis patients in Ethiopia, a cross sectional studies ,BMC infectious disease ,2005, 5:12.

[21] Zacheus Matebesi ,Herman Meulemans and Christiane : Health seeking behavior among clinic-based TB patients, Acta Academic supplementum, 2005(1) : 154-174.

[22] Mohamed Guled Farah, Jens Henning Rygh, Tore W Steen,Randi Selmer, Einar Heldall and Gunnar Bjune :Patient and health care system delays in the start of tuberculosis treatment in Norway, BMC Infectious Diseases2006, 6:33.

[23] Amal Bassili, MD, MPH, DrPH, Akihiro Seita, MD, Samiha Baghdadi, MD, Amin AlAbsi, MD,y Ismail Abdilai:: Diagnostic and Treatment Delay in Tuberculosis in 7 Countries of the Eastern Mediterranean Region, Infect Dis Clin Pract 2008.

[24] Mengiste M Mesfin, Tesfay W Tasew, Israel G Tareke, Girmai WM Mulugeta, and Madeley J:Richard1 Community knowledge, attitudes and practices on pulmonary tuberculosis and their choice of treatment supervisor in Tigray, northern Ethiopia, Ethiop.J.Health Dev. 2005; 19:21-27.

[25] Abebe G, Deribew A, Apers L, Woldemichael K, Shiffa J, et al.: Knowledge, Health Seeking Behavior and Perceived Stigma towards Tuberculosis among TuberculosisSuspectsinaRuralCommunityinsouthwesEthiopi ,2010.

[26] Advocacy, communication and social mobilization for TB control: a guide to developing knowledge, attitude and practice surveys. WHO/HTM/STB/2008.46

[27] Alexis Cambanis, Andy Ramsay, Mohammed A. Yassin and Luis E. Cuevas: Duration and associated factors of patient delay during tuberculosis screening in rural Cameroon Tropical medicine and Interna 2008.

[28] Sushil C Baral, Deepak K Karki and James N Newell: Causes of stigma and discrimination associated with tuberculosis in Nepal, a qualitative study, BMC Public Health 2007.

[29] Karma Jigme Tobgay: health seeking behavior and delays in diagnosis and treatment in patients reporting with cough of three weeks or more to tuberculosis units \& microscopy centre in east Sikkim, Working Paper No. 6 July 2004.

[30] Annual report Bahir Dar zonal health office Jully2010 -June 2011

[31] Naritha Ratha : patient delay for seeking care at health care facilities among pulmonary Tuberculosis patients in pursat province Cambodia,2009. 